\title{
Crescimento e balanço nutricional de mudas de Enterolobium contortsiliquum com aplicação de substratos orgânicos e água residuária
}

\author{
Emanuel França Araújo ${ }^{1 *}$, Adriana Miranda de Santana Arauco², Julian Junio de Jesús Lacerda², Rafael Felippe Ratke², \\ João Carlos Medeiros ${ }^{2}$
}

1 Universidade Federal do Espírito Santo, Av. Governador Lindemberg, 316, CEP 29550-000, Jerônimo Monteiro, Espirito Santo, Brasil

2Universidade Federal do Piauí, BR 135, Planalto Horizonte CEP 64900-000, Bom Jesus, Piauí, Brasil

"Autor correspondente:
emanuelfa.bj@hotmail.com

Termos para indexação:

Bagana de carnaúba

Cama de frango

Dejetos suínos

Index terms:

"Bagana de carnaúba"

Bed aviary

Swine wastewater

\section{Histórico do artigo:}

Recebido em 27/01/2016

Aprovado em 07/06/2016

Publicado em 30/06/2016

doi: 10.4336/2016.pfb.36.86.1135
Resumo - Diante da geração acentuada de resíduos orgânicos sólidos e efluentes, a utilização desses materiais como fonte primária de nutrientes consiste em uma importante prática de gestão ambiental, sobretudo na produção de mudas com ênfase à recuperação de áreas degradadas. Objetivou-se com este trabalho avaliar o crescimento e o balanço nutricional de mudas de tamboril (Enterolobium contortsiliquum (Vell.) Morong) cultivadas em substratos com diferentes formulações e proporções de resíduos orgânicos irrigados com água residuária. Foram testados cinco proporções de composto orgânico e solo: 0:100; 20:80; 40:60; 60:40 e 80:20 v/v, e duas qualidades de água de irrigação: água de abastecimento e água residuária de suinocultura, dispostos em delineamento inteiramente casualizado em esquema fatorial, 5 x 2, com quatro repetições. Aos 90 dias, foram avaliadas as variáveis morfológicas, índices do sistema integrado de diagnose e recomendação e do balanço nutricional médio das mudas. Constatou-se que o resíduo orgânico contribui para o crescimento e o equilíbrio nutricional das mudas. A proporção $80: 20$ mostrou-se a mais indicada à produção de mudas de tamboril. O crescimento e balanço nutricional das mudas foram inferiores nos tratamentos que receberam irrigação com água residuária de suinocultura.

\section{Growth and nutrient balance of Enterolobium contortsiliquum seedlings with addition of organic substrates and wastewater}

\begin{abstract}
Given the strong generation of solid organic waste and wastewater, the use of these materials as a primary source of nutrients is an important practice in environmental management, especially in the production of seedlings with emphasis on degraded areas. The objective of this study was to evaluate growth and nutrient balance of "tamboril" (Enterolobium contortsiliquum (Vell.) Morong) seedlings grown on substrates with different formulations proportions of organic matter irrigated with wastewater. It was tested five ratios of organic composts and soil: 0:100; 20:80; 40:60; 60:40 and 80:20 $\mathrm{v} / \mathrm{v}$. Two procedences of irrigation water was tested: water supply and wastewater from swine farming, arranged in a completely randomized design in a factorial scheme $5 \times 2$, with four replications. At 90 days, we evaluate seedlings morphological variables, the integrate diagnosis recommendation index and the nutrient balance index. The organic residue contributes to seedlings growth and nutritional balance. The proportion 80:20 proved to be the most suitable for "tamboril" seedlings production. Seedlings presented lower growth and nutritional balance when irrigate with swine farm wastewater.
\end{abstract}




\section{Introdução}

A produção de mudas de espécies florestais constitui uma das etapas mais importantes do sistema produtivo, contudo, altamente dependente de insumos. Nesta etapa, o substrato destaca-se em importância devido à influência direta na emergência, enraizamento, retenção de água, nutrição e qualidade das mudas (Sousa et al., 2013; Trazzi et al., 2013; Lustosa Filho et al., 2015).

O aproveitamento de resíduos é uma prática de gestão ambiental prevista na Política Nacional de Resíduos Sólidos (PNRS), Lei n 12.305/2010, principalmente por mitigar os impactos negativos gerados pela sua disposição inadequada (Brasil, 2012). Além do aspecto ambiental, a utilização de resíduos de origem orgânica permite a redução dos custos de produção, principalmente em regiões isoladas onde o acesso a substratos comerciais e fertilizantes minerais são escassos e onerosos. Toledo et al. (2015) reiteram que, devido à existência de diversos tipos de resíduos, é necessário avaliar as diferentes combinações desses materiais na composição de substratos ideais para cada espécie.

A cama de frango é composta de dejetos, penas e do material utilizado no piso do galpão avícola. Quando estabilizada biologicamente, pode suprir parcial ou totalmente o uso de fertilizantes minerais na produção vegetal. Trazzi et al. (2013), concluíram que mudas de teca (Tectona grandis) produzidas em substratos formulados com $35 \%$ de cama de frango apresentaram os maiores valores das variáveis morfológicas analisadas.

A bagana é o resíduo agroindustrial da extração da cera da carnaúba (Copernicia prunifera), amplamente disponível no estado do Piauí. Apresenta características físicas e químicas favoráveis para composição de substratos. Lustosa Filho et al. (2015) verificaram que a adição desse material ao substrato promoveu um aumento no crescimento e na qualidade de mudas de jatobá (Hymenaea stigonocarpa).

Além dos resíduos sólidos, o uso de águas residuárias constitui uma alternativa viável ao crescente processo de escassez hídrica e ao elevado consumo de água nos viveiros florestais. Segundo Cromer (1980), o reuso de águas na atividade florestal constitui um método seguro por não envolver produção de alimentos e nem riscos à saúde, além de ser uma forma de conservação da água potável.

Dentre as atividades agropecuárias que mais geram águas residuárias no Brasil está a suinocultura, com mais de 100 milhões $\mathrm{m}^{3}$ ano $^{-1}$ (Suszek et al., 2005). Utilizada na fertirrigação de mudas de Eucalyptus grandis, a água residuária de suinocultura propicia uma antecipação no tempo de formação das mudas de 90 para 60 dias (Pelissari et al., 2009).

O tamboril (Enterolobium contortisiliquum) é uma espécie arbórea pertencente à família Fabaceae, nativa do bioma Mata Atlântica, e que apresenta ampla distribuição nos diferentes biomas brasileiros (Lorenzi, 2009). A espécie é indicada para o reflorestamento de áreas desmatadas e degradadas (Araújo \& Paiva Sobrinho, 2011). Em fase de mudas, pesquisas mostram que a adição de materiais orgânicos pode influenciar positivamente o crescimento desta espécie (Nóbrega et al., 2008; Saidelles et al., 2009; Sousa et al., 2013).

Portanto, a hipótese deste estudo é que maiores proporções de resíduos orgânicos na composição do substrato e águas residuárias tratadas na irrigação potencializam o crescimento e melhoram o estado nutricional de mudas florestais. Assim, objetivou-se avaliar o crescimento e o balanço nutricional de mudas de tamboril cultivadas em substratos com diferentes proporções de cama de frango e bagana de carnaúba, irrigadas com água de abastecimento e água residuária de suinocultura.

\section{Material e métodos}

O experimento foi conduzido no viveiro pertencente à Universidade Federal do Piauí em Bom Jesus, PI, durante os meses de julho a outubro de 2014. O município de Bom Jesus está situado nas coordenadas 0904'S e $44^{\circ} 21^{\prime} \mathrm{W}$ com altitude média de $277 \mathrm{~m}$. O clima da região é quente e semiúmido do tipo Aw (Köppen), com precipitação média de 900 a $1.200 \mathrm{~mm}^{2} \mathrm{ano}^{-1}$ e duas estações bem definidas, a seca no período de maio a outubro e a chuvosa de novembro a abril (Andrade Júnior et al., 2004).

O solo utilizado no experimento foi classificado como um Latossolo Amarelo distrófico típico, de textura franco-arenosa e foi coletado na profundidade de 20 a $40 \mathrm{~cm}$, sob vegetação nativa de cerrado. Antes da instalação do experimento, o solo foi caracterizado quanto aos atributos químicos e físicos, conforme Donagema et al. (2011). Os valores encontrados foram: $\mathrm{pH} \mathrm{em} \mathrm{CaCl}_{2}=3,9 ; \mathrm{P}=5,3 \mathrm{mg} \mathrm{dm}^{-3} ; \mathrm{K}=20,0 \mathrm{mg} \mathrm{dm}^{-3}$; $\mathrm{Ca}^{2+}=0,3 \mathrm{cmol}_{\mathrm{c}} \mathrm{dm}^{-3} ; \mathrm{Mg}^{2+}=0,3 \mathrm{cmol}_{\mathrm{c}} \mathrm{dm}^{-3} ; \mathrm{Al}^{3+}=$ $1,8 \mathrm{cmol}_{\mathrm{c}} \mathrm{dm}^{-3} ; \stackrel{\mathrm{c}}{\mathrm{H}}+\mathrm{Al}=3,2 \mathrm{cmol}_{\mathrm{c}} \mathrm{dm}^{-3} ; \mathrm{c}=14,67 \%$; 
$\mathrm{CTC}=3,75 \mathrm{cmol}_{\mathrm{c}} \mathrm{dm}^{-3}$; matéria orgânica $=7,0 \mathrm{~g} \mathrm{dm}^{-3}$; $\mathrm{C}=4,06 \mathrm{~g} \mathrm{dm}^{-3}$; areia: $673 \mathrm{~g} \mathrm{~kg}^{-1}$, silte: $52 \mathrm{~g} \mathrm{~kg}^{-1} \mathrm{e}$ argila: $275 \mathrm{~g} \mathrm{~kg}^{-1}$.

$\mathrm{O}$ experimento foi disposto em delineamento inteiramente casualizado, em esquema fatorial $5 \times 2$, com quatro repetições. Cada unidade experimental foi composta por uma muda de tamboril (Enterolobium contortsiliquum (Vell.) Morong), plantada em saco de polietileno com as dimensões de $18 \mathrm{~cm}$ de diâmetro por $27 \mathrm{~cm}$ de altura. Os substratos estudados consistiram de cinco combinações, em termos percentuais volumétricos da bagana da carnaúba (Copernicia prunifera (Mill.) H.E. Moore), cama de frango e solo: 00-00-100 (controle experimental); 10-10-80; 20-20-60; 30-30-40 e 40-40-20 (v/v), respectivamente. Assim, os tratamentos foram considerados como cinco proporções do material orgânico $(0,20,40,60$ e $80 \%)$ na composição do substrato final; e duas fontes de água para a irrigação das mudas: água residuária de suinocultura e água de abastecimento. Não foram fornecidas outras fontes de nutrientes e o solo não foi corrigido quanto à acidez.

Os materiais orgânicos, bagana de carnaúba e cama de frango também foram caracterizados antes da implantação do experimento. Os atributos químicos da bagana de carnaúba foram: $\mathrm{N}=24,8 \mathrm{~g} \mathrm{~kg}^{-1} ; \mathrm{P}=$ $1,0 \mathrm{~g} \mathrm{~kg}^{-1} ; \mathrm{K}=2,6 \mathrm{~g} \mathrm{~kg}^{-1} ; \mathrm{Ca}=4,5 \mathrm{~g} \mathrm{~kg}^{-1} ; \mathrm{Mg}=$ $1,5 \mathrm{~g} \mathrm{~kg}^{-1} ; \mathrm{S}=2,8 \mathrm{~g} \mathrm{~kg}^{-1}$, segundo Silva (2009), com densidade aparente de $0,19 \mathrm{~g} \mathrm{~cm}^{-3}$. Enquanto, os atributos químicos da cama de frango foram: $\mathrm{N}=19,0 \mathrm{~g} \mathrm{~kg}^{-1} ; \mathrm{P}$ $=58,0 \mathrm{~g} \mathrm{~kg}^{-1} ; \mathrm{K}=34,0 \mathrm{~g} \mathrm{~kg}^{-1} ; \mathrm{Ca}=26,0 \mathrm{~g} \mathrm{~kg}^{-1} ; \mathrm{Mg}=$ $6,1 \mathrm{~g} \mathrm{~kg}^{-1} ; \mathrm{S}=5,2 \mathrm{~g} \mathrm{~kg}^{-1}$, com densidade aparente de $0,28 \mathrm{~g} \mathrm{~cm}^{-3}$.

Foram coletadas amostras de substrato ao final do experimento para caracterização química (Tabela 1), utilizando a metodologia descrita por Silva (2009).

Tabela 1. Caracterização química dos substratos para a produção de mudas de tamboril (Enterolobium contortsiliquum), em viveiro.

\begin{tabular}{cccccccccc}
\hline Irrigação & $\begin{array}{c}\text { Substrato (resíduo } \\
\text { orgânico: solo) (v/v) }\end{array}$ & $\begin{array}{c}\mathbf{p H} \\
\left(\mathbf{C a C l}^{\mathbf{2}}\right)\end{array}$ & $\mathbf{N}$ & $\mathbf{P}$ & $\mathbf{K}$ & $\mathbf{C a}$ & $\mathbf{M g}$ & $\mathbf{C / N}$ & $\begin{array}{c}\text { M.O. } \\
\mathbf{( d a g ~ k g}^{-1} \mathbf{)}\end{array}$ \\
\hline \multirow{3}{*}{$\begin{array}{c}\text { Água de } \\
\text { abastecimento }\end{array}$} & $0-100$ & 3,9 & 2,0 & 0,1 & 0,4 & 0,04 & 0,01 & 11,7 & 4,0 \\
& $20-80$ & 5,3 & 1,2 & 6,4 & 8,2 & 0,42 & 0,17 & 9,9 & 2,0 \\
& $40-60$ & 6,3 & 4,2 & 16,6 & 7,6 & 0,60 & 0,34 & 12,7 & 9,2 \\
& $60-40$ & 6,1 & 8,0 & 18,3 & 4,6 & 0,86 & 0,41 & 13,5 & 18,6 \\
Água & $80-20$ & 5,8 & 8,6 & 20,6 & 26,6 & 1,34 & 0,58 & 13,5 & 20,0 \\
residuária de & $0-100$ & 5,2 & 2,2 & 0,9 & 3,7 & 0,14 & 0,07 & 10,9 & 4,1 \\
suinocultura & $20-80$ & 5,6 & 3,1 & 12,0 & 1,7 & 0,56 & 0,30 & 11,5 & 6,1 \\
& $40-60$ & 6,3 & 4,8 & 17,8 & 11,5 & 0,68 & 0,35 & 12,9 & 10,6 \\
& $60-40$ & 6,1 & 7,0 & 16,5 & 8,3 & 0,62 & 0,41 & 13,4 & 16,1 \\
\hline
\end{tabular}

Onde: $\mathrm{C} / \mathrm{N}=$ relação carbono:nitrogênio; M.O. = matéria orgânica.

A água residuária utilizada era obtida de um reator sequencial em batelada (RSB) anaeróbico instalado no Setor de Suinocultura do Departamento de Zootecnia da UFPI. A caracterização química da água residuária de suinocultura, realizada segundo Alcarde (2009), apresentou os seguintes resultados: $\mathrm{pH}=7,25$; condutividade elétrica $=4,15 \mathrm{mS} \mathrm{cm}{ }^{-1} ; \mathrm{N}=0,37 \mathrm{~g} \mathrm{~kg}^{-1}$; $\mathrm{P}=0,06 \mathrm{~g} \mathrm{~kg}^{-1} ; \mathrm{K}=0,28 \mathrm{~g} \mathrm{~kg}^{-1} ; \mathrm{Ca}=0,07 \mathrm{~g} \mathrm{~kg}^{-1} ; \mathrm{Mg}$ $=0,06 \mathrm{~g} \mathrm{~kg}^{-1} ; \mathrm{S}=0,03 \mathrm{~g} \mathrm{~kg}^{-1} ; \mathrm{Na}=2,2 \mathrm{~g} \mathrm{~kg}^{-1}$. A outra fonte utlizada para irrigação das mudas foi água de abastecimento $(\mathrm{AB})$.

As sementes de tamboril foram submetidas ao processo de quebra de dormência (Aquino, 2009), sendo utilizadas três sementes em cada unidade experimental. Aos 20 dias após a semeadura foi realizado o raleio, mantendose apenas uma planta por unidade experimental. Para evitar que a água residuária comprometesse o processo de germinação das sementes e emergência das plântulas, a aplicação da água residuária foi iniciada aos 30 dias após a semeadura. As mudas foram irrigadas duas vezes ao dia, sendo a necessidade avaliada através de pesagem, mantendo-se a umidade em $80 \%$ da capacidade de vaso.

Aos 90 dias após a semeadura, as mudas foram avaliadas quanto ao diâmetro do coleto (DC), por meio de leituras com paquímetro digital; altura $(\mathrm{H})$, determinada da superfície do substrato até o meristema 
apical, com auxílio de régua graduada $(\mathrm{mm})$ e a área foliar total (AF), utilizando-se medidor de área foliar (modelo LI-3100C ${ }^{\circledR}$ ). Após as avaliações morfológicas, o material vegetal foi seco em estufa a $65{ }^{\circ} \mathrm{C}$ com circulação forçada de ar, sendo pesado em balança analítica com precisão de 0,1 g para avaliação da massa seca da parte aérea (MSPA), massa seca de raízes (MSR) e massa seca total (MST). As folhas com pecíolo foram destacadas do caule para a determinação dos teores foliares de N, P, K, Ca, Mg e S, conforme Silva (2009).

Foi calculado o índice de qualidade de Díckson (IQD) com a fórmula: IQD = MST/[(H/D) + (MSPA/MSR) $]$ (Dickson et al., 1960). Também foram calculados os índices do sistema integrado de diagnose e recomendação (DRIS) e os índices de balanço nutricional médio (IBN médio), com o auxílio do programa INAF - Interpretação de Análise Foliar (Garcia, 2013). Para o cálculo das funções das razões dos nutrientes foi utilizado o método proposto por Beaufils (1973) com o fator k igual a 10 .

Os dados foram submetidos à análise de variância pelo teste $\mathrm{F}$ ao nível de 0,05 de probabilidade. As duas fontes de água para irrigação foram comparadas pelo teste de Tukey ao nível de 0,05 e 0,01 de probabilidade de probabilidade e as doses dos materiais orgânicos através de análise de regressão. As análises foram realizadas utilizando-se o programa SISVAR 4.2 (Ferreira, 2011). Também foram calculados os coeficientes de correlação de Pearson entre as variáveis de crescimento das mudas e o IBN médio.

\section{Resultados e discussão}

Ao final do período de avaliação, verificou-se interação $(\mathrm{p} \leq 0,01)$ entre os fatores qualidade da água de irrigação e as proporções de resíduo orgânico na composição do substrato para a variável área foliar, indicando haver interdependência entre os fatores estudados na expressão dessa característica. As proporções de resíduos promoveram diferenças significativas $(\mathrm{p} \leq 0,05)$ para as variáveis: altura, diâmetro do coleto, massa seca da parte aérea, massa seca total e índice de qualidade de Díckson. Verificou-se ainda efeito da qualidade da água $(\mathrm{p} \leq 0,05)$ para todas as variáveis estudadas, com exceção da massa seca da parte aérea.

Para o diâmetro do coleto das mudas de tamboril, foi observada tendência de crescimento linear crescente para as proporções, alçando o valor máximo $(8,27 \mathrm{~mm}$ planta $^{-1}$ ) no tratamento constituído na proporção 80:20 de resíduo orgânico e solo (Figura 1a). Em relação à altura, o crescimento foi quadrático, em que a máxima $\mathrm{H}$ $\left(93,9 \mathrm{~cm} \mathrm{planta}^{-1}\right)$ foi obtida com a proporção estimada de 68,1:31,9 de resíduo orgânico e solo (Figura 1b).

Para a massa seca da parte aérea e massa seca total, o modelo linear foi o que melhor explicou o efeito das proporções, onde os valores máximos 14,63 $\mathrm{g}_{\text {plantas }}{ }^{-1}$ e 22,64 g plantas $^{-1}$ foram obtidos na proporção 80:20 de resíduo orgânico e solo (Figuras 1c; 1d).

O máximo valor da área foliar $\left(899,11 \mathrm{~cm}^{2}\right.$ planta $\left.^{-1}\right)$ foi obtido na proporção estimada 73,4:26,6 de resíduo orgânico e solo associado a irrigação com água de abastecimento, com tendência de crescimento quadrático (Figura 1e). As mudas irrigadas com água residuária apresentaram tendência de crescimento linear para as proporções, sendo que a área foliar máxima $\left(678,95 \mathrm{~cm} \mathrm{planta}^{-1}\right)$ foi obtida na proporção $80: 20 \mathrm{de}$ resíduo orgânico e solo.

Em relação ao índice de qualidade de Díckson, Gomes et al. (2002) defendem que quanto maior o valor, melhor o padrão de qualidade das mudas. Observou-se efeito individual das proporções de resíduo orgânico, onde o maior valor estimado $(1,38)$ foi obtido na proporção 80:20 de resíduo orgânico e solo, seguindo o mesmo comportamento observado para a massa seca da parte área e massa seca total (Figura 1f).

Este comportamento é justificado pelo aumento da fertilidade dos substratos, por meio da adição do material orgânico à base de bagana de carnaúba e cama de frango em proporções crescentes (Tabela 1). Dessa forma, é possível deduzir que as mudas desta espécie são bastante responsivas à adição de materiais orgânicos ao substrato de cultivo, conforme destacado na literatura (Nóbrega et al., 2008; Sousa et al., 2013).

Ao avaliar o efeito de proporções de composto de lixo de origem urbana como substrato na produção de mudas de tamboril, Nóbrega et al. (2008) obtiveram o maior crescimento em diâmetro do coleto, massa seca da parte aérea, de raízes e total e índice de qualidade de Díckson na proporção 80:20.

Também foi constatado por Saidelles et al. (2009) que o tamboril na fase de muda responde positivamente à adubação orgânica. Avaliando a influência de diferentes proporções de casca de arroz carbonizada e solo como substrato, esses autores concluíram que o substrato na proporção 50:50 possibilitou a produção de mudas de tamboril com adequado padrão de qualidade. 

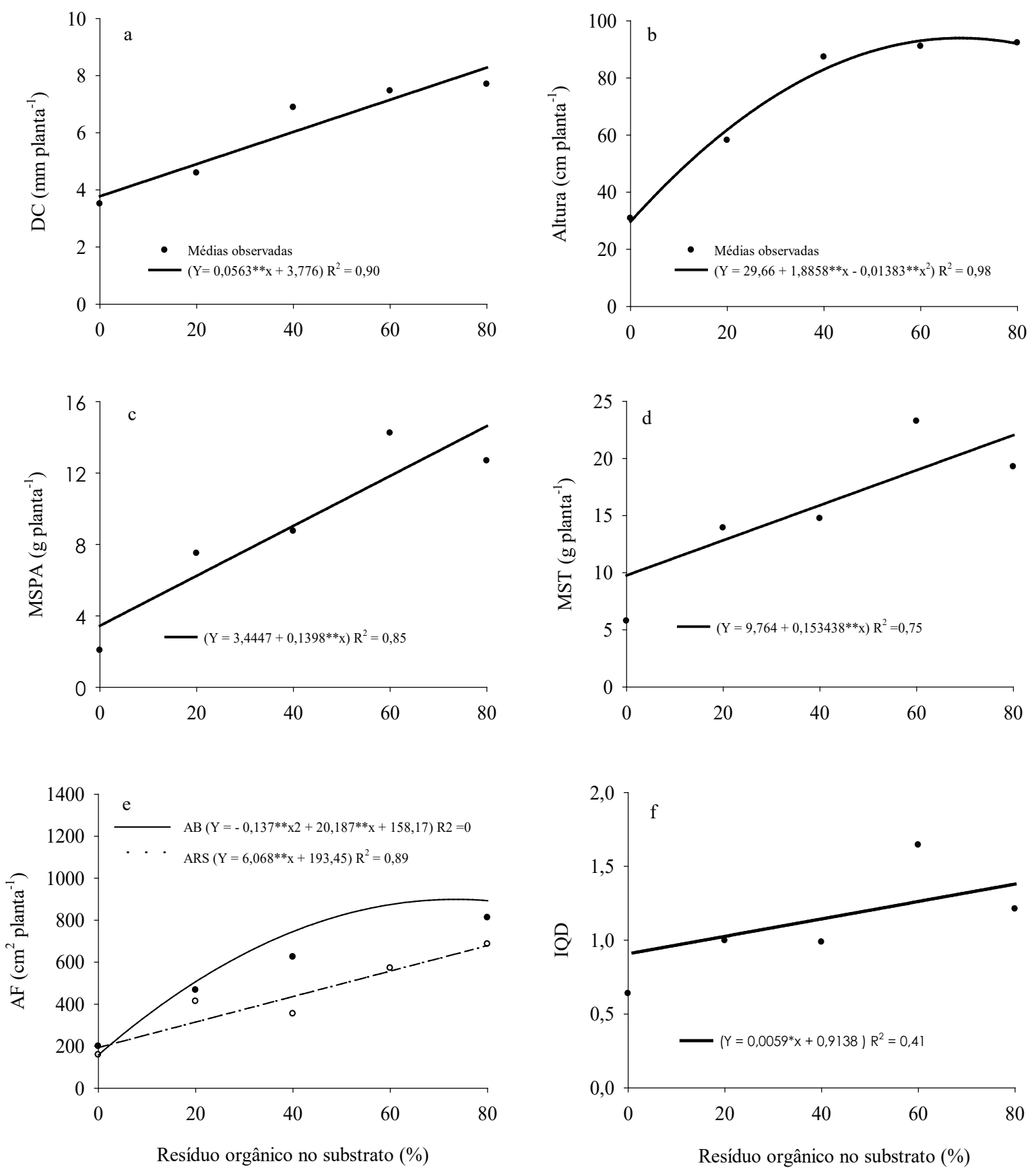

Figura 1. Diâmetro do coleto (a); altura (b); massa seca da parte aérea (c); massa seca total (d); área foliar (e); índice de qualidade de Díckson (f) das mudas de tamboril (Enterolobium contortsiliquum), cultivadas em diferentes proporções de resíduo orgânico e solo. * e ** = significativo a 5\% e 1\% de probabilidade, respectivamente. 
Ao analisar proporções de estipes de buritizeiro semidecompostos no crescimento de mudas, Sousa et al. (2013) verificaram que a incorporação desse material na composição do substrato possibilitou um maior crescimento e maior qualidade de mudas de tamboril em relação ao tratamento que continha apenas solo, resultados esses que estão de acordo com os obtidos neste estudo.

Verificou-se que a irrigação com água residuária da suinocultura promoveu crescimento inferior do diâmetro do coleto, altura, massa seca de raízes e massa seca total, o que refletiu no baixo valor de índice de qualidade Díckson (Figura 2f).

Estes resultados são divergentes dos encontrados em espécies de Eucalyptus obtidos por Batista et al. (2014), que verificaram efeito positivo com água residuária de suinocultura até a concentração de $50 \%$ sobre as características morfológicas e nutricionais de mudas de Eucalyptus urophylla, e por Pelissari et al. (2009), que observaram que esse efluente, na fertirrigação, proporcionou maior altura e diâmetro do coleto de mudas de Eucalyptus grandis.
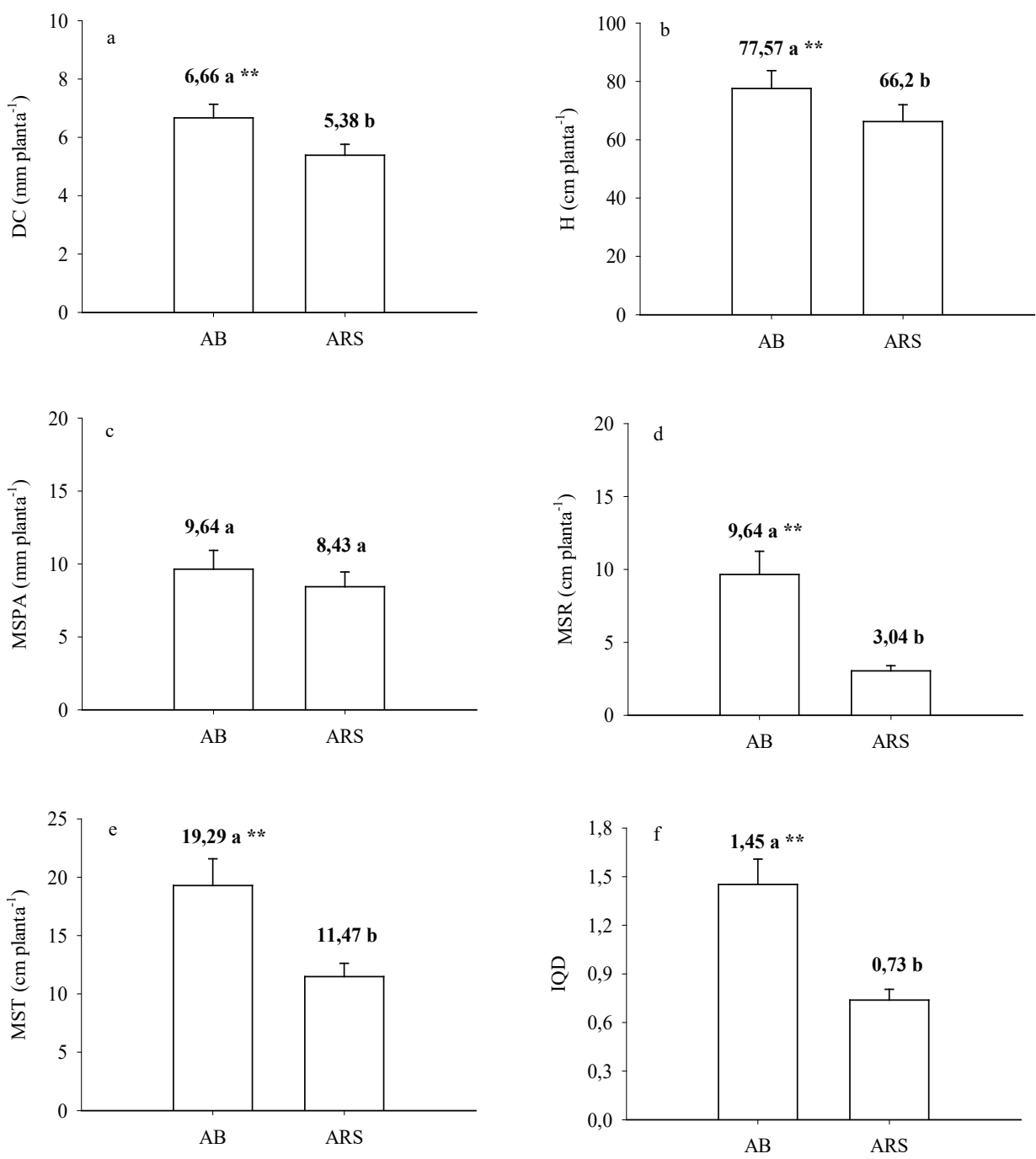

Figura 2. Diâmetro do coleto (a); altura (b); massa seca da parte aérea (c); massa seca de raízes (d); massa seca total (e); e índice de qualidade de Díckson (f) das mudas de tamboril (Enterolobium contortsiliquum), irrigadas com água de abastecimento $(\mathrm{AB})$ e água residuária de suinocultura (ARS). $*$ e $* *=$ significativo a $5 \%$ e $1 \%$ de probabilidade, respectivamente. 
O menor crescimento das mudas de tamboril submetidas à fertirrigação com água residuária de suinocultura pode ser explicado em função das características químicas deste efluente, onde os valores médios da condutividade elétrica apresentaram severa restrição de uso, segundo a classificação de Ayers \& Westcot (1999), por possuírem valores maiores que $3,0 \mathrm{dS} \mathrm{m}^{-1}$ ou $\mathrm{mS} \mathrm{cm}{ }^{-1}$. A condutividade elétrica é um parâmetro que expressa a concentração de sais ionizados em solução. Vários autores afirmam que o estresse salino em decorrência de alterações fisiológicas, hormonais e do potencial osmótico, pode restringir a absorção de água e de nutrientes, causando redução generalizada do metabolismo da planta (Farias et al., 2009; Alves et al., 2011; Cavalcante et al., 2011). Por esta razão, esse é um dos itens que deve ser considerado na escolha do material.

Conforme verificado na Tabela 2, houve variação dos índices DRIS das mudas de tamboril em função dos fatores avaliados. Quando os índices DRIS assumem valores negativos denota que há uma deficiência em relação aos demais nutrientes e quando assumem valores positivos, indica excesso. Quanto mais próximos de zero estiverem os índices DRIS, mais próximo do equilíbrio nutricional estará a planta (Walworth et al., 1986). A irrigação com água residuária foi responsável pelos maiores desvios dos índices DRIS, provavelmente devido à sua composição nutricional desbalanceada (Tabela 2).

Analisando-se o diagnóstico do estado nutricional através dos índices DRIS, é possível calcular o IBN médio, considerando o somatório dos índices DRIS em módulo, dividido pelo número de nutrientes envolvidos. Em teoria, quanto menor o valor do IBN médio, menor o desequilíbrio nutricional das plantas e, potencialmente, com maior produção (Malavolta et al., 1997; Urano et al., 2006), desde que os demais fatores não se encontrem limitantes, como temperatura e umidade.

Tabela 2. Teores médios de macronutrientes (TN), índice DRIS (ID) e índice de balanço nutricional em mudas de tamboril (Enterolobium contortsiliquum).

\begin{tabular}{|c|c|c|c|c|c|c|c|c|}
\hline \multirow{2}{*}{$\begin{array}{c}\text { Resíduo } \\
\text { orgânico } \\
(\%)\end{array}$} & \multicolumn{8}{|c|}{ Água de abastecimento } \\
\hline & & $\mathbf{N}$ & $\mathbf{P}$ & $\mathbf{K}$ & $\mathbf{C a}$ & Mg & $\mathbf{S}$ & IBN médio \\
\hline & & ----- & 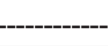 & $\mathrm{g} \mathrm{kg}^{-1}$ & --- & -ב---- & & \\
\hline \multirow{2}{*}{0} & $\mathrm{TN}$ & 32,40 & 1,80 & 16,00 & 5,10 & 5,00 & 1,70 & 77,83 \\
\hline & ID & 85,93 & $-181,42$ & $-52,08$ & 58,48 & 2,87 & 86,23 & \\
\hline \multirow{2}{*}{20} & $\mathrm{TN}$ & 34,80 & 3,80 & 22,00 & 6,60 & 6,00 & 2,40 & 44,81 \\
\hline & ID & $-6,29$ & $-5,84$ & $-57,36$ & 45,53 & $-64,95$ & 88,91 & \\
\hline \multirow{2}{*}{40} & $\mathrm{TN}$ & 36,00 & 4,00 & 25,00 & 5,30 & 5,20 & 2,20 & 37,32 \\
\hline & ID & 13,34 & 26,88 & $-0,29$ & 16,39 & $-111,68$ & 55,36 & \\
\hline \multirow{2}{*}{60} & $\mathrm{TN}$ & 34,00 & 3,80 & 22,00 & 4,80 & 7,00 & 1,60 & 4,38 \\
\hline & ID & 4,48 & 1,60 & $-4,47$ & 7,07 & $-1,33$ & $-7,36$ & \\
\hline \multirow{3}{*}{80} & $\mathrm{TN}$ & 36,00 & 4,20 & 26,80 & 4,70 & 8,00 & 2,00 & 4,42 \\
\hline & ID & $-4,27$ & $-1,29$ & 4,40 & $-7,71$ & 1,59 & 7,29 & \\
\hline & \multicolumn{8}{|c|}{ Água residuária de suinocultura } \\
\hline \multirow{2}{*}{0} & $\mathrm{TN}$ & 41,00 & 1,80 & 24,80 & 4,80 & 5,20 & 1,80 & 89,35 \\
\hline & ID & 142,58 & $-245,34$ & 56,40 & 31,15 & $-22,70$ & 37,91 & \\
\hline \multirow{2}{*}{20} & $\mathrm{TN}$ & 42,00 & 3,10 & 38,80 & 6,20 & 7,00 & 3,10 & 62,27 \\
\hline & ID & 29,25 & $-128,31$ & 62,46 & 19,24 & $-58,50$ & 75,85 & \\
\hline \multirow{2}{*}{40} & $\mathrm{TN}$ & 37,00 & 3,60 & 48,00 & 6,90 & 7,60 & 2,00 & 72,40 \\
\hline & ID & $-18,94$ & $-76,54$ & 183,08 & 34,11 & $-43,65$ & $-78,07$ & \\
\hline \multirow{2}{*}{60} & $\mathrm{TN}$ & 39,00 & 4,00 & 37,20 & 8,50 & 8,10 & 1,90 & 49,89 \\
\hline & ID & $-19,92$ & $-49,35$ & 87,67 & 62,00 & $-23,87$ & $-56,54$ & \\
\hline \multirow{2}{*}{80} & $\mathrm{TN}$ & 38,60 & 3,30 & 32,00 & 7,60 & 8,00 & 1,70 & 47,70 \\
\hline & ID & 5,96 & $-89,47$ & 71,16 & 57,60 & 8,37 & $-53,61$ & \\
\hline
\end{tabular}


Dessa forma, verifica-se que mudas cultivadas nos substratos com maiores proporções de material orgânico, associadas com a irrigação com água de abastecimento, apresentaram maior equilíbrio nutricional (Tabela 2).

O IBN médio apresentou forte correlação negativa com todas as variáveis avaliadas, com destaque para a altura e o diâmetro do coleto, variáveis de obtenção não destrutivas, além do índice de qualidade de Díckson, que é o principal indicador de qualidade morfológica utilizado em mudas florestais (Tabela 3). Esses resultados estão em consonância com os de diferentes trabalhos nos quais o IBN médio apresenta alta correlação negativa com variáveis relacionadas à produtividade das culturas (Terra et al., 2007; Guindani et al., 2009; Teixeira et al., 2015).

Tabela 3. Matriz de correlação de Pearson entre as variáveis de crescimento e índice de balanço nutricional médio das mudas de tamboril (Enterolobium contortsiliquum).

\begin{tabular}{|c|c|c|c|c|c|c|c|}
\hline Parâmetros & $\mathbf{H}$ & AF & MSPA & MSR & MST & IQD & IBN médio \\
\hline $\mathrm{DC}$ & $0,953 * *$ & $0,860 * *$ & $0,872 * *$ & 0,622 & $0,860 * *$ & $0,747^{*}$ & $-0,862 * *$ \\
\hline $\mathrm{H}$ & 1,000 & $0,869^{* *}$ & $0,898 * *$ & 0,545 & $0,834 * *$ & $0,683^{*}$ & $-0,806^{* *}$ \\
\hline $\mathrm{AF}$ & & 1,000 & $0,939 * *$ & $0,725^{*}$ & $0,956^{* *}$ & $0,869 * *$ & $-0,946^{* *}$ \\
\hline MSPA & & & 1,000 & 0,534 & $0,889 * *$ & $0,735^{*}$ & $-0,864 * *$ \\
\hline MST & & & & 1,000 & $0,862 * *$ & $0,954 * *$ & $-0,832 * *$ \\
\hline MST & & & & & 1,000 & $0,958 * *$ & $-0,969 * *$ \\
\hline IQD & & & & & & 1,000 & $-0,917 * *$ \\
\hline IBN médio & & & & & & & 1,000 \\
\hline
\end{tabular}

$\mathrm{DC}=$ Diâmetro do coleto; $\mathrm{H}=$ altura; $\mathrm{AF}=$ área foliar; $\mathrm{MSPA}=$ massa seca da parte aérea; $\mathrm{MSR}=$ massa seca de raízes; $\mathrm{MST}=$ massa seca total; IQD = índice de qualidade de Díckson; IBNm = índice de balanço nutricional médio. * e ** = significativo ao nível de $5 \%$ e $1 \%$ de probabilidade pelo teste $\mathrm{F}$, respectivamente.

O composto formulado à base de bagana de carnaúba e cama de frango adicionado ao solo constitui uma opção tecnicamente viável como material básico na formulação de substratos na produção de mudas de tamboril. Apesar da fertirrigação com água residuária de suinocultura promover crescimento inferior das mudas, recomenda-se a avaliação da sensibilidade de outras espécies florestais, monitoramento da salinidade desse efluente e o desenvolvimento de metodologias de reuso, tendo em vista o elevado consumo de água nos viveiros e o atual cenário crítico de escassez hídrica constatado em certas regiões.

\section{Conclusões}

Proporções crescentes de resíduos orgânicos na composição de substrato contribuíram para o melhor desenvolvimento, por propiciarem o equilíbrio nutricional das mudas de tamboril.

O substrato na proporção de 80:20 (composto orgânico e solo) mostrou-se o mais indicado para a produção de mudas de tamboril.

O crescimento e balanço nutricional das mudas de tamboril foram inferiores nos tratamentos submetidos à fertirrigação com água residuária de suinocultura.

\section{Agradecimento}

A Fundação de Amparo à Pesquisa do Estado do Piauí, FAPEPI, pela bolsa de pós-graduação para o primeiro autor.

\section{Referências}

Alcarde, J. C. Manual de análise de fertilizantes. Piracicaba: FEALQ, 2009. 259 p.

Alves, F. A. L. et al. Efeito do $\mathrm{Ca}^{2+}$ externo no conteúdo de $\mathrm{Na}^{+}$e $\mathrm{K}^{+}$ em cajueiros expostos a salinidade. Revista Brasileira de Ciências Agrárias, v. 6, p. 602-608, 2011. DOI: 10.5039/agraria.v6i4a1257.

Andrade Júnior, A. S. et al. Atlas climatológico do estado do Piauí. Teresina: Embrapa Meio Norte, 2004. 150 p. (Embrapa Meio Norte. Documentos, 101).

Aquino, A. F. M. A. G. Superação de dormência de orelha-de negro [Enterolobium contortsiliquum (Vell.) Morong]. Revista Verde de Agroecologia e Desenvolvimento Sustentável, v. 4, p. 69-75, 2009.

Araújo, A. P. \& Paiva Sobrinho, S. Germinação e produção de mudas de tamboril (Enterolobium contortiliquum (Vell.) Morong) em diferentes substratos. Revista Árvore, v. 35, n. 3, p. 581-588, 2011. DOI: 10.1590/S0100-67622011000400001.

Ayers, R. S. \& Westcot, D. W. A qualidade de água na agricultura. 2. ed. 2. ed. Campina Grande: UFPB, 1999. 135 p. (FAO. Estudos irrigação e drenagem). 
Batista, R. O. et al. O efeito da água residuária da suinocultura no desenvolvimento e qualidade de mudas de Eucalyptus urophylla. Ciência Florestal, v. 24, n. 1, p. 127-135, 2014. DOI: 10.5902/1980509813330.

Beaufils, E. R. Diagnosis and recommendation integrated system (DRIS). a general scheme for experimentation and calibration based on principles develop from research in plant nutrition. Pietermaritzburg: University of Natal, 1973. 132 p. (Soil Science Bulletin, 1).

Brasil. Política nacional de resíduos sólidos: institui a Política Nacional de Resíduos Sólidos; altera a Lei n ${ }^{\circ} 9.605$, de 12 de fevereiro de 1998; e dá outras providências. 2. ed. Brasília, DF: Câmara dos Deputados, Edições Câmara, 2012. 73 p. (Série legislação, 81).

Cavalcante, L. F. et al. Fontes e níveis da salinidade da água na formação de mudas de mamoeiro cv. sunrise solo. Semina: Ciências Agrárias, v. 31, n. 4, p. 1281-1290, 2011. DOI: 10.5433/1679-0359.2010v31n4Sup1p1281.

Cromer, R. N. Irrigation of radiata pine with wastewater: a review of the potential for tree growth and water renovation. Australian Forest, v. 43, p. 87-100, 1980. DOI: 10.1080/00049158.1980.10674252.

Dickson, A. et al. Quality appraisal of white spruce and white pine seedling stock in nurseries. The Forestry Chronicle, v. 36, n. 1, p. 10-13, 1960. DOI: 10.5558/tfc36010-1.

Donagema, G. K. et al. Manual de métodos de análise de solos. Rio de Janeiro: Embrapa Solos, 2011. 225 p.

Farias, S. G. G. D. et al. Estresse salino no crescimento inicial e nutrição mineral de gliricídia [Gliricidia sepium (Jacq.) Kunth ex Steud] em solução nutritiva. Revista Brasileira de Ciência do Solo, v. 33, p. 1499-1505, 2009. DOI: 10.1590/S0100-06832009000500040.

Ferreira, D. F. Sisvar: um sistema computacional de análise estatística. Revista Ciência e Agrotecnologia, v. 35, n. 6, p. 10391042, 2011. DOI: 10.1590/S1413-70542011000600001.

Garcia, M. B. INAF: software para interpretação de análise foliar. 2013.

Gomes, J. M. et al. Parâmetros morfológicos na avaliação da qualidade de mudas de Eucalyptus grandis. Revista Árvore, v. 26, n. 6, p. 655664, 2002. DOI: 10.1590/S0100-67622002000600002.

Guindani, R. H. P. et al. DRIS na avaliação do estado nutricional do arroz irrigado por inundação. Revista Brasileira de Ciência do Solo, v. 33, n. 1, p. 109-118. 2009. DOI: 10.1590/S010006832009000100012 .

LORENZI, H. Árvores brasileiras: manual de identificação e cultivo de plantas arbóreas nativas do Brasil. 3. ed. Nova Odessa: Instituto Plantarum, 2009. v. 2384 p. il. color.

Lustosa Filho, J. F. et al. Influence of organic substrates on growth and nutrient contents of jatobá (Hymenaea stigonocarpa). African Journal of Agricultural Research, v. 10, n. 26, p. 2544-2552, 2015. DOI: 10.5897/AJAR2015.9781.

Malavolta, E. et al. Avaliação do estado nutricional das plantas.
2. ed. Piracicaba, São Paulo: POTAFOS, 1997. 201 p.

Nóbrega, R. S. A. et al. Efeito do composto de lixo urbano no crescimento inicial de mudas de Enterolobium contortisiliquum (Vell.) Morong. Scientia Forestalis, v. 36, p. 181-189, 2008.

Pelissari, R. et al. Lodo têxtil e água residuária da suinocultura na produção de mudas de Eucalyptus grandis (W, Hill ex Maiden). Engenharia Agrícola, v. 29, n. 2, p. 288-300, 2009. DOI: 10.1590/ S0100-69162009000200012.

Saidelles, F. L. F. et al. Casca de arroz carbonizada como substrato para produção de mudas de tamboril-da-mata e garapeira. Semina: Ciências Agrárias, v. 30, n. 4, p. 1173-1186, 2009.

Silva, F. C. D. A. S. Manual de análises químicas de solos, plantas e fertilizantes. 2. ed. Brasília, DF: Embrapa Informação Tecnológica, 2009. $627 \mathrm{p}$.

Sousa, W. C. et al. Fontes de nitrogênio e caule decomposto de Mauritia flexuosa na nodulação e crescimento de Enterolobium contortsiliquum. Revista Árvore, v. 37, n. 5, p. 969-979. 2013. DOI: 10.1590/S0100-67622013000500019.

Suszek, M. et al. Uso de água residuária da suinocultura na bioestabilização de resíduos verdes urbanos. Revista Brasileira de Engenharia Agrícola e Ambiental, v. 9, suplemento, p. 176-180, 2005.

Teixeira, L. A. J. et al. Normas DRIS e níveis críticos de nutrientes para videira 'Niagara Rosada' cultivada na região de Jundiaí-SP. Revista Brasileira Fruticultura, v. 37, n. 1, p. 247-255, 2015. DOI: 10.1590/0100-2945-409/13.

Terra, M. M. et al. Avaliação do estado nutricional da videira 'Itália' na região de São Miguel Arcanjo-SP, utilizando o sistema integrado de diagnose e recomendação. Revista Brasileira de Fruticultura, v. 29, n. 3, p. 710-716, 2007. DOI: 10.1590/S010029452007000300055.

Toledo, F. H. S. F. et al. Compost of residues of pulp and paper in the production of eucalyptus seedlings. Revista Brasileira de Engenharia Agrícola e Ambiental, v. 19, n. 7, p. 711-716, 2015. DOI: 10.1590/1807-1929/agriambi.v19n7p711-716.

Trazzi, P. A. et al. Substratos de origem orgânica para produção de mudas de teca (Tectona grandis Linn. F.). Ciência Florestal, v. 23, n. 3, p. 401-409, 2013. DOI: 10.5902/1980509810551.

Urano, E. O. M. et al. Avaliação do estado nutricional da soja. Pesquisa Agropecuária Brasileira, v. 41, n. 9, p. 1421-1428, 2006.

Walworth, J. L. et al. Preliminary DRIS norms for alfalfa in the southeastern united states and a comparison with midwestern norms. Agronomy Journal, v. 78, n. 6, p. 1046-1052, 1986. DOI: 10.2134/ agronj1986.00021962007800060022x. 
